\title{
Prototecosis en caninos en Costa Rica: ¿cuándo sospechar y qué buscar?
}

\section{Canine Protothecosis in Costa Rica: What to Look For and When to Suspect? Prototecose em caninos na Costa Rica: quando suspeitar e o que procurar?}

\author{
Natalia B. Campos-González ${ }^{1}$, Alejandra Calderón-Hernández², Érika Valverde-Altamirano³, Alejandro \\ Alfaro-Alarcón ${ }^{4 凶}$
}

1. Escuela de Medicina Veterinaria, Universidad Nacional, Costa Rica. E mail: nbcamposg@gmail.com

2. Laboratorio de Micología, Escuela de Medicina Veterinaria, Universidad Nacional, Costa Rica. E mail: alejandra.calderon. hernandez@una.ac.cr

3. Nutrinac Salud Digestiva Veterinaria, Clínica Veterinaria, San José, Costa Rica. E mail: info@nutrinac.com

4. Departamento de Patología, Escuela de Medicina Veterinaria, Universidad Nacional, Costa Rica. E mail: alejandro.alfaro. alarcon@una.cr*

Recibido: 19 de abril de 2021 Corregido: 7 de julio de 2021 Aceptado: 19 de julio de 2021

\begin{abstract}
Resumen
La prototecosis es una enfermedad causada por algas saprófitas, no clorofílicas, unicelulares y oportunistas del género Prototheca, que afecta, principalmente, a animales con inmunodeficiencias. En caninos, con la forma intestinal, se puede presentar inicialmente como diarrea sanguinolenta, pudiendo progresar a un cuadro sistémico; mientras que en felinos, generalmente, genera lesiones cutáneas. En Costa Rica, Prototheca zopfii es la especie que se ha identificado con mayor frecuencia, y Prototheca wickerhamii, una vez. El diagnóstico de esta enfermedad se puede realizar mediante distintas técnicas como: citología, histopatología, endoscopía, cultivo, reacción en cadena de polimerasa (PCR), método bioquímico, entre otros. El tratamiento recomendado es anfotericina B e itraconazol, los cuales son efectivos, principalmente, en felinos. Sin embargo, en caninos, con presentación sistémica, no existe un tratamiento efectivo. En caso de lesiones cutáneas, se recomienda la resección quirúrgica.
\end{abstract}

Palabras clave: diarrea crónica, canino, Prototheca, P. zopfi, P. wickerbamii

\begin{abstract}
Protothecosis is a disease caused by unicellular, achlorophilic, saprophyte, and opportunistic algae of the genus Prototheca, affecting mainly animals with immunodeficiencies. In canines with the intestinal form, it causes bloody diarrhea, which can progress to a systemic disease. At the same time, skin lesions are common in felines. In Costa Rica, Prototheca zopfii is the species identified with the highest frequency, and Prototheca wickerhamii was identified once. Prototheca spp. can be diagnosed using different techniques, such as cytology, histopathology, endoscopy, culture, polymerase chain reaction, biochemical method, and others. Currently, the recommended treatment is the use of amphotericin $B$ and itraconazole, which have been reported to be effective in felines; however, there is no effective treatment in canines with systemic disease. Surgery is recommended in cases of cutaneous lesions.
\end{abstract}

\Autor de correspondencia: alejandro.alfaro.alarcon@una.cr 
Keywords: chronic diarrhea, canine, Prototheca, P. zopfi, P. wickerhamii

\begin{abstract}
Resumo
A prototecose é uma doença causada por algas saprofíticas, não clorofílicas, unicelulares e oportunistas do gênero Prototheca, que afeta principalmente animais com imunodeficiências. Em caninos, com a forma intestinal, pode causar, inicialmente, diarréia hemorrágica, podendo evoluir para um quadro sistêmico; enquanto em felinos, geralmente, causa lesões cutâneas. Na Costa Rica, Prototheca zopfii é a espécie mais frequentemente identificada, e Prototheca wickerhamii foi uma vez identificada. O diagnóstico desta doença pode ser feito por diferentes técnicas como: citologia, histopatologia, endoscopia, cultura, reação em cadeia da polimerase (PCR), método bioquímico, entre outras. O tratamento recomendado é o uso de anfotericina B e o itraconazol, que são eficazes, principalmente, em felinos. Porém, em caninos, com apresentação sistêmica, não existe um tratamento eficaz. Para lesões de pele, a ressecção cirúrgica é recomendada.
\end{abstract}

Palavras-chave: diarréia crônica, canina, Prototheca, P. zopfii, P. wickerhamii

\title{
Introducción
}

Prototheca spp. es un alga unicelular, no clorofílica, saprofita y oportunista que se encuentra en el ambiente. Puede ser aislada en: excretas de animales, desechos alimenticios, tierra, savia de árboles, lodo de pastizales, lagos, ríos, aguas estancadas y residuales domiciliares y de lecherías. La principal ruta de infección, en caninos, es la vía oral; mientras que en felinos y humanos se adquiere por trauma (Hollingsworth et al., 2000; Manino et al., 2014; Palm, 2014; Ribeiro et al., 2009; Samanta, 2015; Strunck et al., 2004). La prototecosis es una enfermedad inusual, asociada a casos de inmunosupresión o disfunción inmunológica hereditaria (Carfora et al., 2017; Nelson \& Couto, 2014; Souza et al., 2009). Afecta: principalmente, a humanos, bovinos, caninos y felinos, aunque también se ha observado casos en equinos, ovinos y suinos (Samanta, 2015; Souza et al., 2009; Stenner et al., 2007). En caninos, el órgano blanco inicial es el tracto gastrointestinal, pudiendo evolucionar a una infección sistémica afectando órganos como: bazo, corazón, hígado, huesos, ojos, piel, riñones, sistema nervioso central y tracto respiratorio, en los cuales puede inducir lesiones piogranulomatosas. A nivel mundial, se han identificado cinco especies de Prototheca patógenas de mamíferos: $P$. blaschkeae, $P$. cutis, P. miyajii, P. wickerhamii, y P. zopfii, (Carfora et al., 2017). Sin embargo, las especies más prevalentes son: $P$. wickerbamii y la $P$. zopfii asociadas a procesos cutáneos y sistémicos, respectivamente. El cuadro sistémico es más común en caninos que presentan principalmente: sinología intestinal, nerviosa, ocular y renal (Samanta, 2015; Souza et al., 2009; Stenner et al., 2007; Young et al., 2012,).

\section{Cuadros clínicos}

En caninos, el desarrollo de la enfermedad tiene curso lento con pronóstico reservado. Por lo general, los signos clínicos se inician en el tracto gastrointestinal, afectando principalmente al colon. Los signos clínicos más comunes son hematoquecia (Fig. 1) con pérdida de peso y colitis (Fig. 2). Estos pueden desarrollarse varios meses antes de presentar sintomatología sistémica. Otros hallazgos reportados son: anemia, anorexia, leucocitosis, linfadenopatías, pirexia, polidipsia y poliuria. Entre las lesiones oculares las panoftalmitis son 


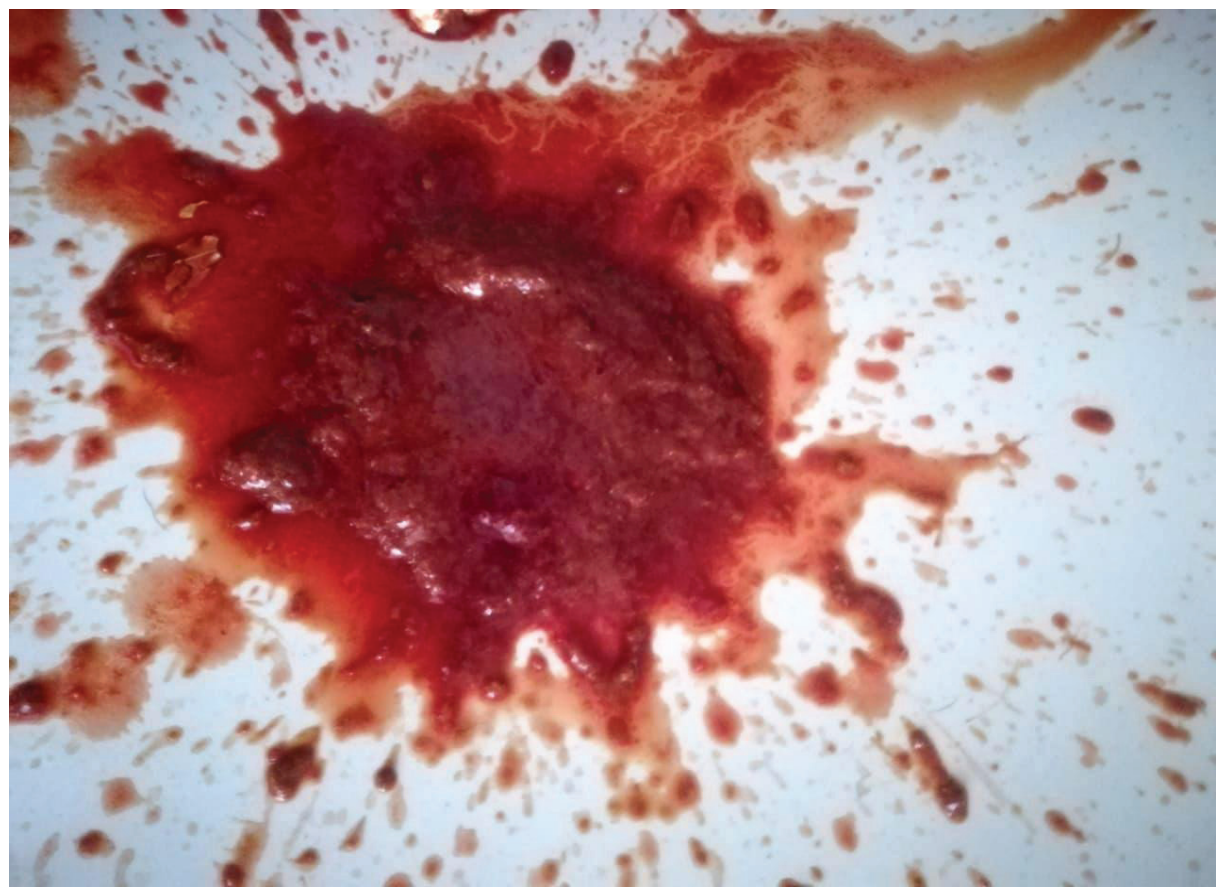

Fig. 1. Deposición fecal mucosanguinolenta de canino con prototecosis digestiva. (ValverdeAltamirano, E., 2020)

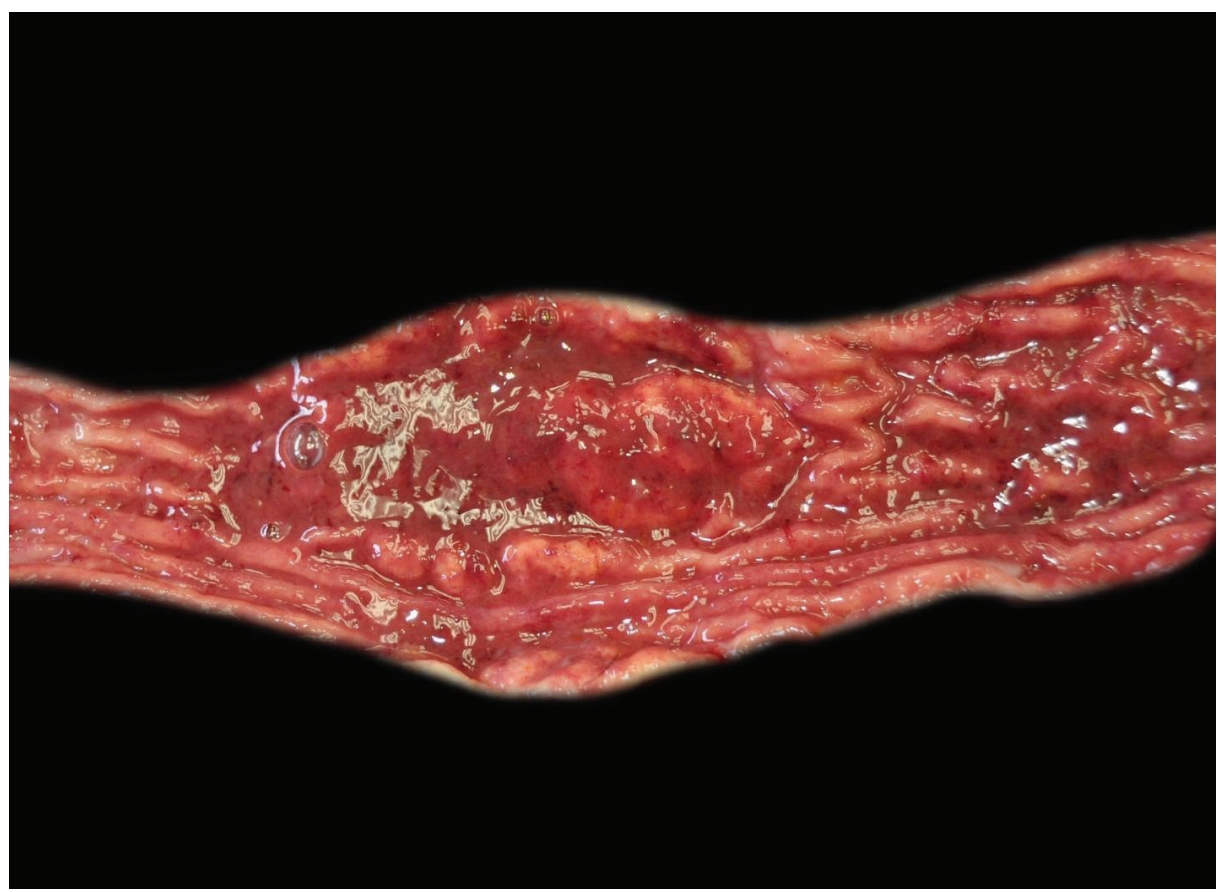

Fig. 2. Colon, colitis piogranulomatosa y hemorrágica asociada a Prototheca zopfii. (AlfaroAlarcón, A., 2021). 


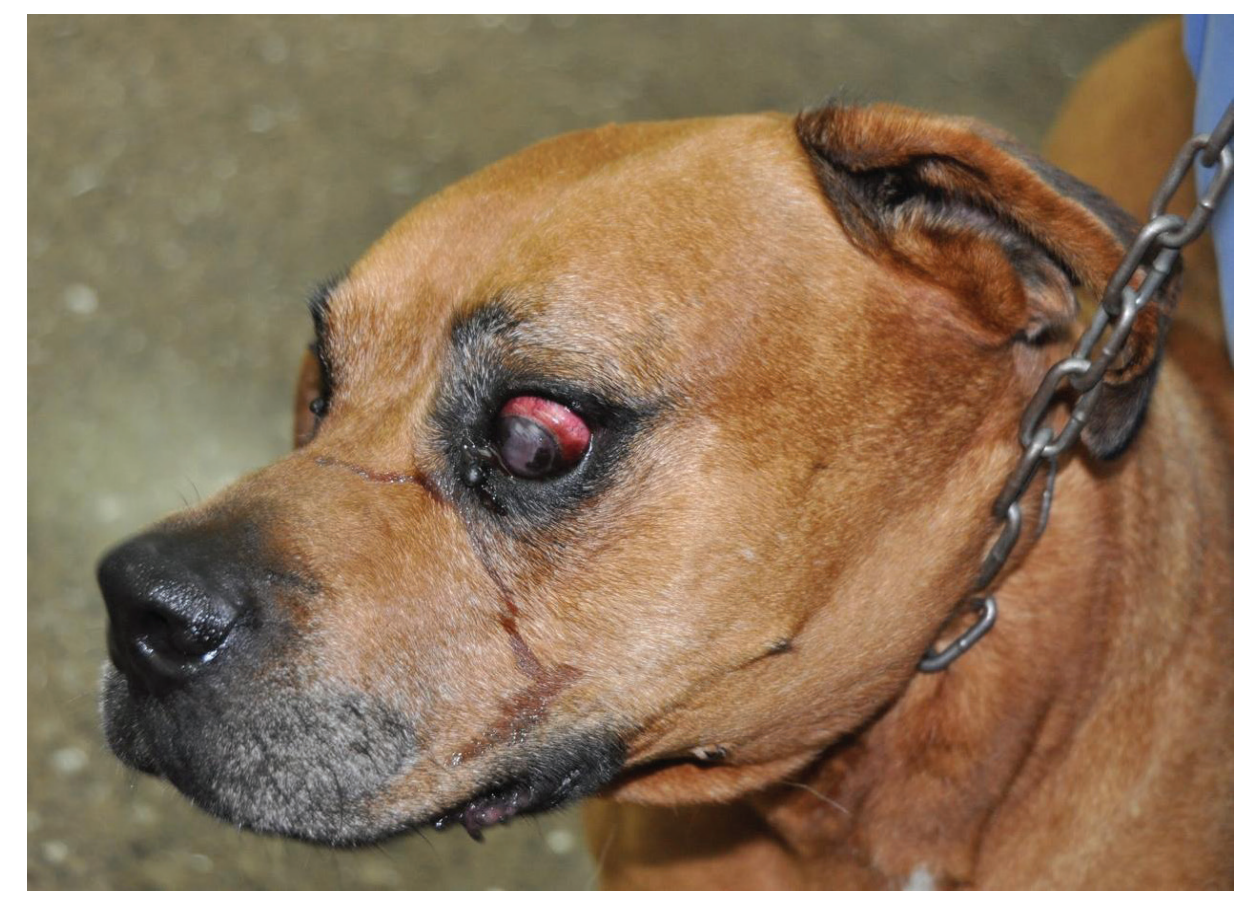

Fig. 3. Globo ocular, exoftalmia, endoftalmitis piogranulomatosa, Prototheca zopfii. (AlfaroAlarcón, A., 2021).

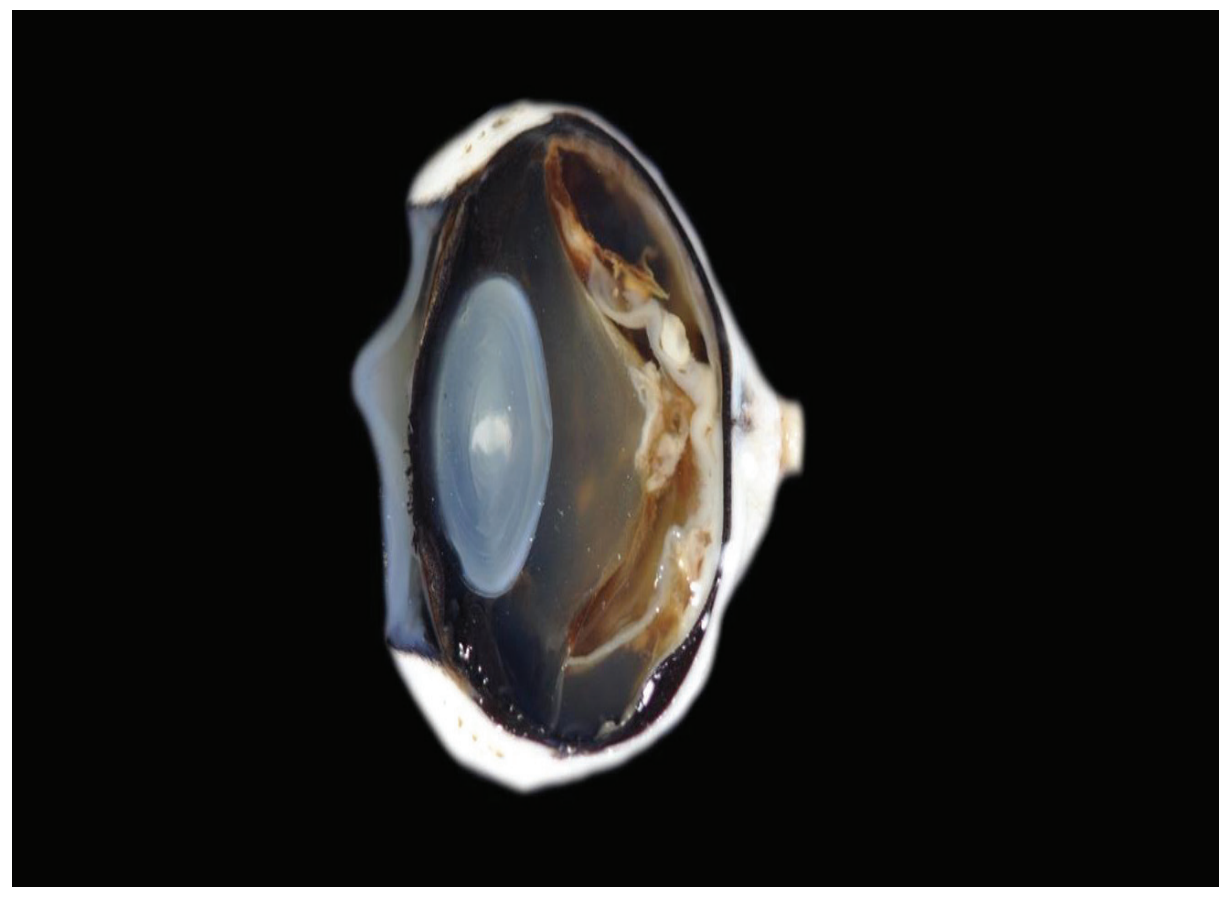

Fig. 4. Globo ocular, endoftalmitis piogranulomatosa con desprendimiento de retina. (Alfaro-Alarcón, A., 2021). 


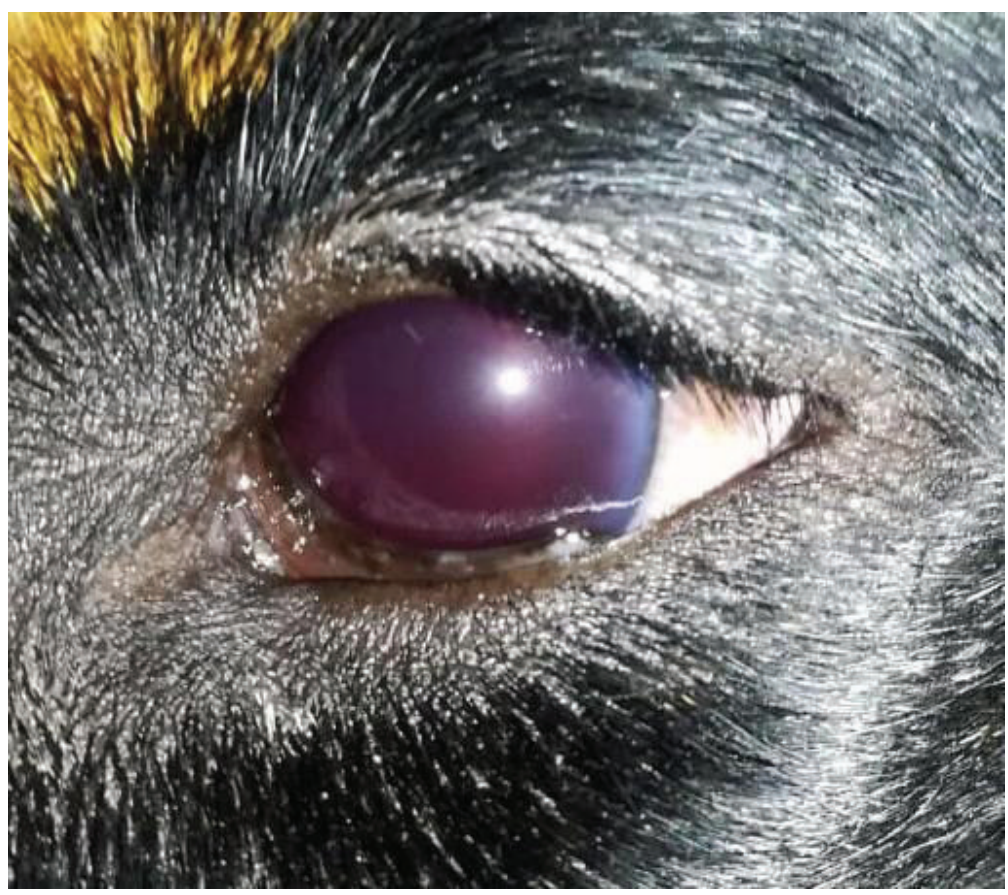

Fig. 5. Canino con uveítis y desprendimiento de retina causado por Prototheca zopfi. (Valverde-Altamirano, E., 2020).

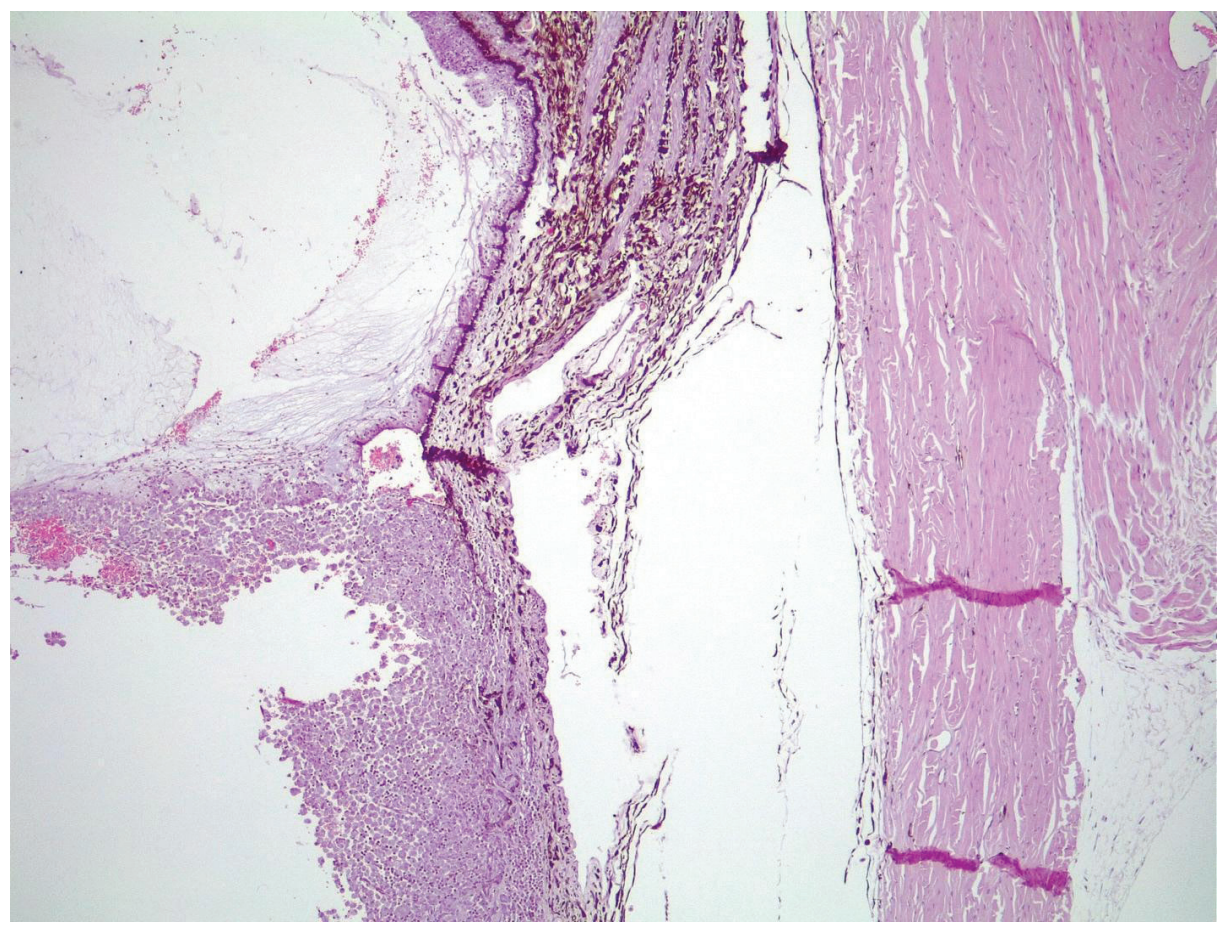

Fig. 6. Histopatología de globo ocular, endoftalmitis piogranulomatosa con desprendimiento de retina y presencia de masivas cantidades de esporangios (estructuras tipo levaduras) H\&E (200x). (Alfaro-Alarcón, A., 2021). 
frecuentes (Fig. 3) seguidas por glaucoma y desprendimiento de retina (Fig. 4-6) (Souza et al., 2009; Stenner et al., 2007; Strunck et al., 2004).

En caso de comprometimiento del sistema nervioso central, se puede observar: ataxia, convulsiones, depresión, dolor cervical, paresia, signos vestibulares y sordera (Font et al., 2014; Nelson \& Couto, 2014; Stenner et al., 2007). Por otra parte, el análisis del líquido cefalorraquídeo se caracteriza por presentar pleocitosis eosinofílica, linfocítica o neutrofílica (Pressler et al., 2005; Young et al., 2012). Las lesiones cutáneas se caracterizan por desarrollar nódulos firmes, úlceras y/o exudado costroso, generalmente ubicadas en el tronco, uniones mucocutáneas y extremidades. También, se ha reportado lesiones en: el plano nasal, región frontal, escroto, base de la cola y la pinna (Ettinger et al., 2010; Greene, 2012; Strunck et al., 2004). El comprometimiento del sistema respiratorio incluye: descarga nasal serosa o sanguinolenta, rinitis piogranulomatosa, disnea, estertores y nódulos en las narinas (Fig. 7); además, en la mucosa nasal se pueden observar úlceras con superficie fibrinonecrotizante, que se extienden desde el vestíbulo nasal hasta las conchas nasales (Macêdo et al., 2008; Schöniger et al., 2016;

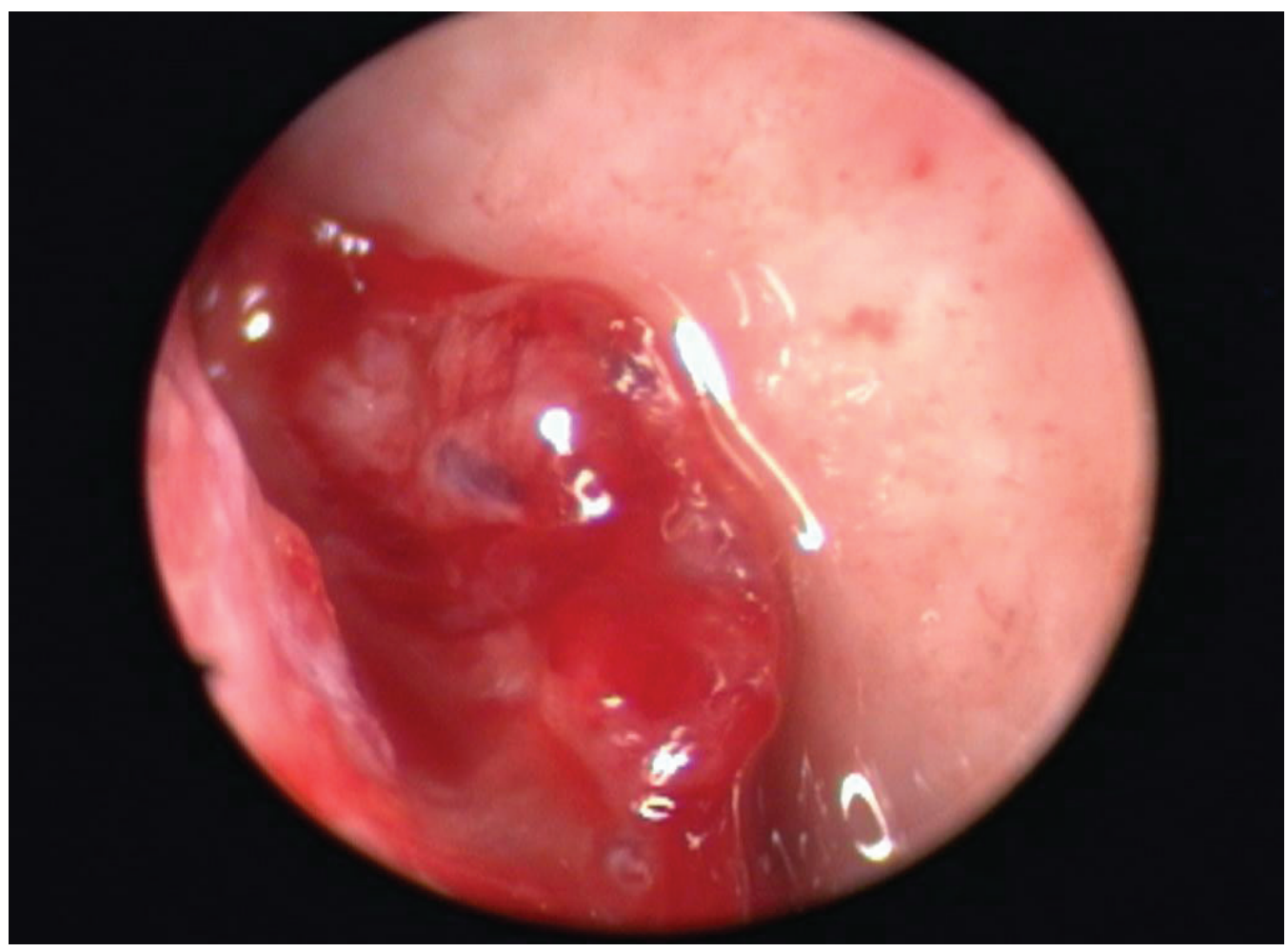

Fig. 7. Hiperplasia epitelial en cornete nasal de un canino. (Valverde-Altamirano, E., 2020). 
Rev. Ciencias Veterinarias, Vol. 40, N 1, [1-17], E-ISSN: 2215-4507, enero-junio, 2022 DOI: https://doi.org/10.15359/rcv.40-1.2

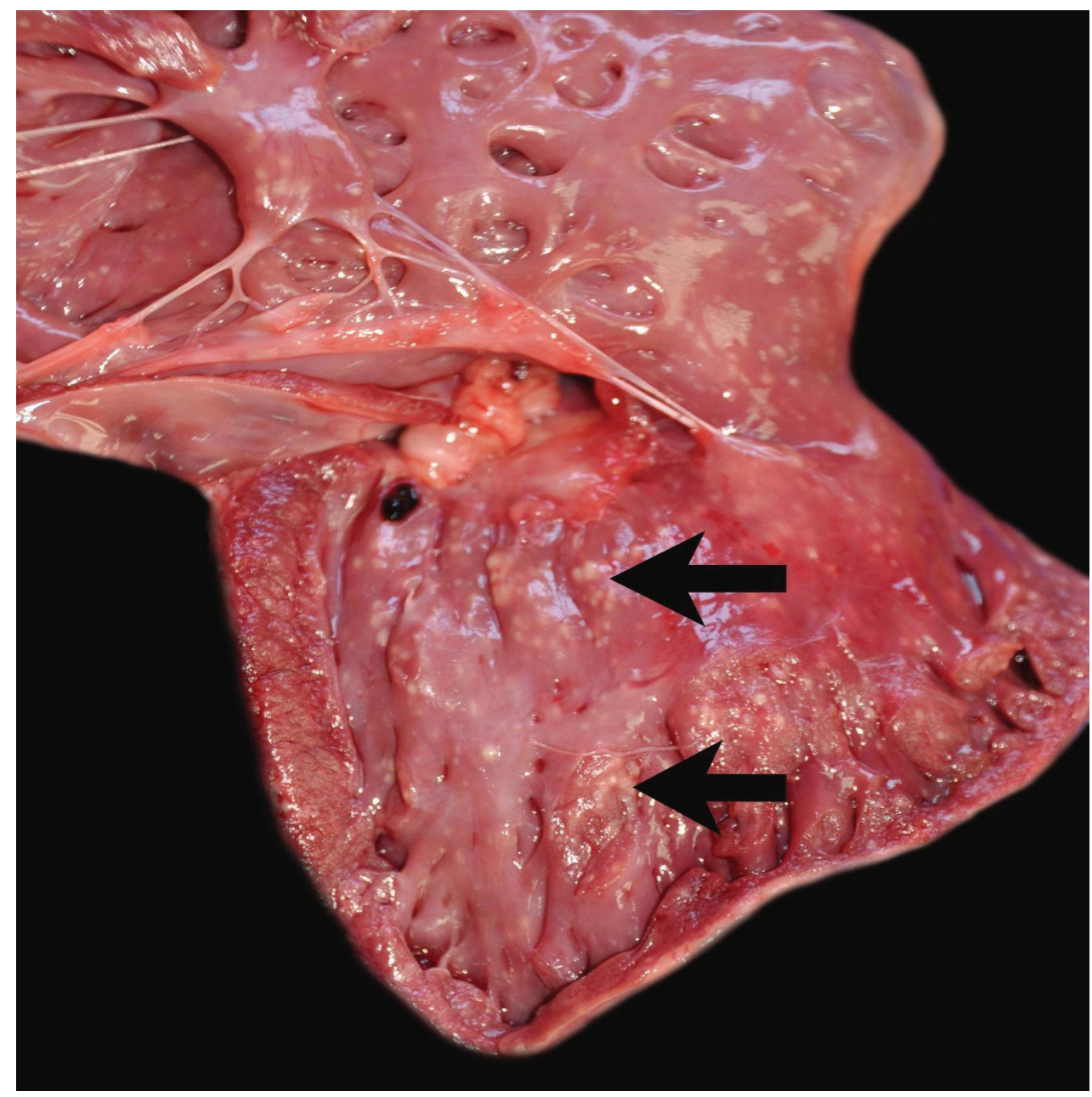

Fig. 8. Endocardio ventricular derecho, miocarditis piogranulomatosa multifocal extensiva. (Alfaro-Alarcón, A., 2021). 


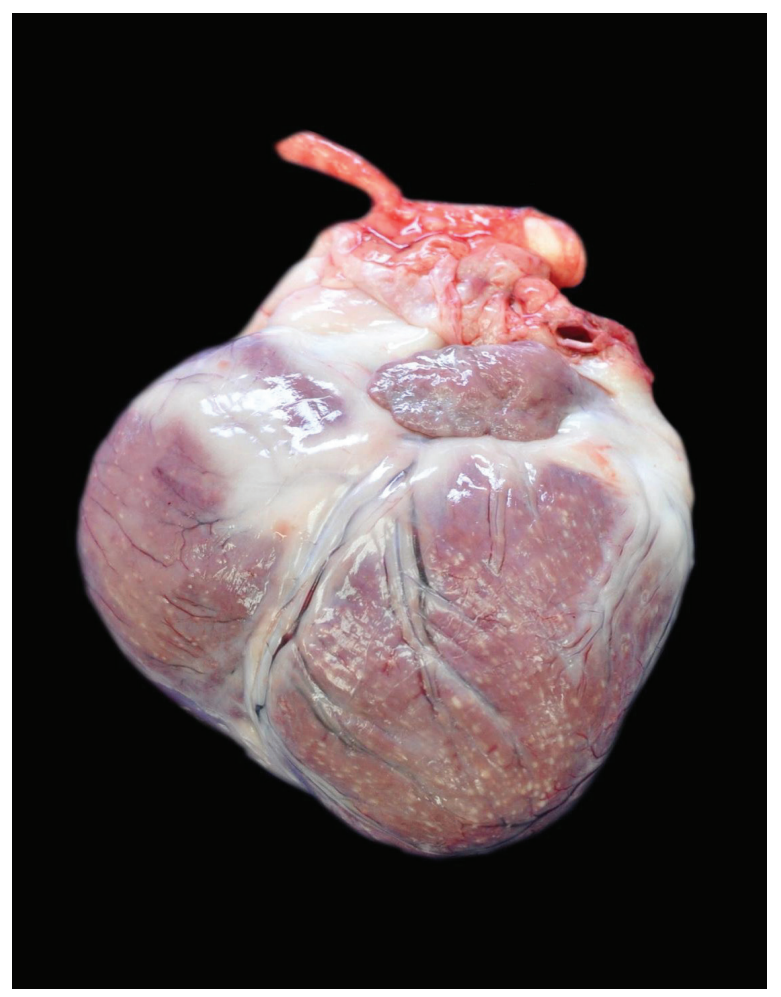

Fig. 9. Corazón, miocarditis piogranulomatosa multifocal extensiva. (Alfaro-Alarcón, A., 2021).

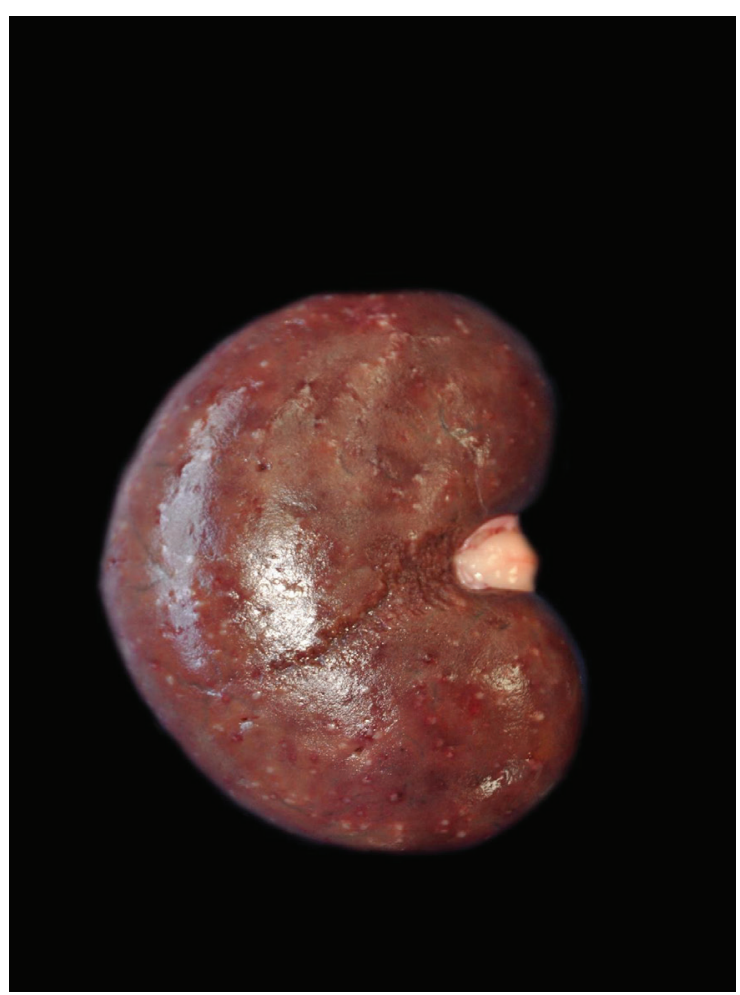

Fig. 10. Riñón, glomerulonefritis piogranuloamtosa asociada a la presencia de múltiples lesiones puntiformes de 0.1-0.2 cm de diámetro. (Alfaro-Alarcón, A., 2021).

Stenner et al., 2007). En los órganos internos, en la superficie serosa, se observa la formación de nódulos de 1-2 mm de diámetro (Fig. 8), color blanco a beige, localizados principalmente en: colon, miocardio (Fig. 9), ojos y riñones (Fig.10) (Souza et al., 2009; Vince et al., 2014).

\section{Diagnóstico}

El diagnóstico certero de esta patología está basado en el análisis con: citología, histopatología o cultivo del tejido afectado. Las muestras clínicas, remitidas para la detección de este agente, dependen de las regiones anatómicas afectadas. Por ejemplo, en casos de lesiones intestinales, deben ser colectadas heces; en casos de mastitis, muestras de leche deben ser remitidos al laboratorio; en casos de infecciones sistémicas: orina, sangre o muestras de tejido deben ser analizadas (Samanta, 2015). El hemograma y las químicas séricas tienen poco valor diagnóstico. En la histopatología, la Prototheca se observa como estructuras (esporangios) de forma ovoide/redondeada de 4-30 $\mu \mathrm{m}$ de diámetro, con citoplasma basofílico, agranular, con núcleo central basofílico y pared celular hialina gruesa con doble refracción (Fig. 11) con numerosas endosporas (Fig. 12). También, se puede observar granulomas con áreas de necrosis rodeado de un infiltrado inflamatorio linfohistioplasmocitario o piogranulomatoso (Fig. 13). Se recomienda utilizar las tinciones Hematoxilina \& Eosina (Fig. 14), Giemsa, Ácido Peryódico de Schiff(PAS), o Nitrato de Plata Metenamina de Gomori (GMS). (Font et al., 2014; Hollingsworth, 2000; Nelson \& Couto, 2014; Souza et al., 2009; Strunck et al., 2004; Young et al., 2012). 


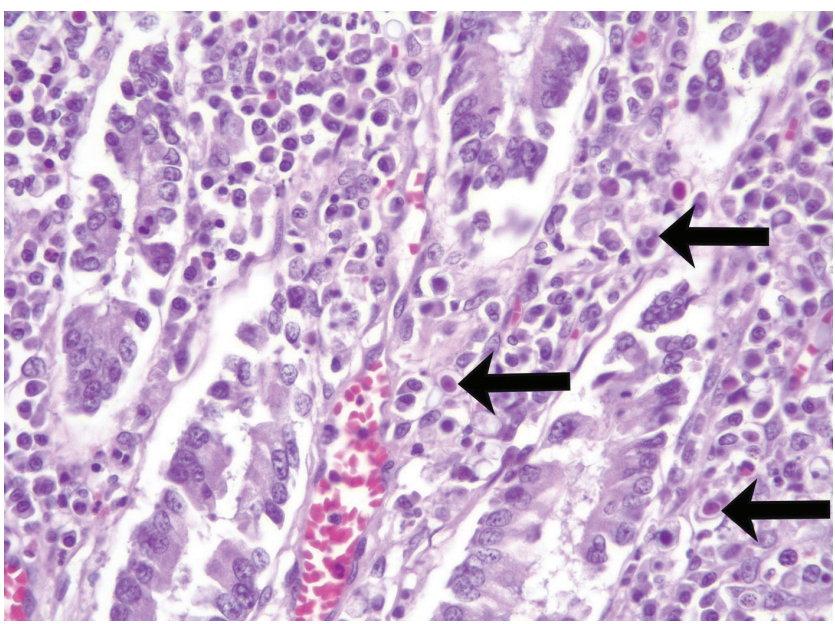

Fig. 11. Histopatología de colon, colitis piogranulomatosa con presencia de masivas cantidades de esporangios, Prototheca zopfii $\mathrm{H} \& \mathrm{E}$ (400x). Se pueden observar organismos esporulados (flecha superior) y no esporulados (flechas inferiores). (AlfaroAlarcón, A., 2021).

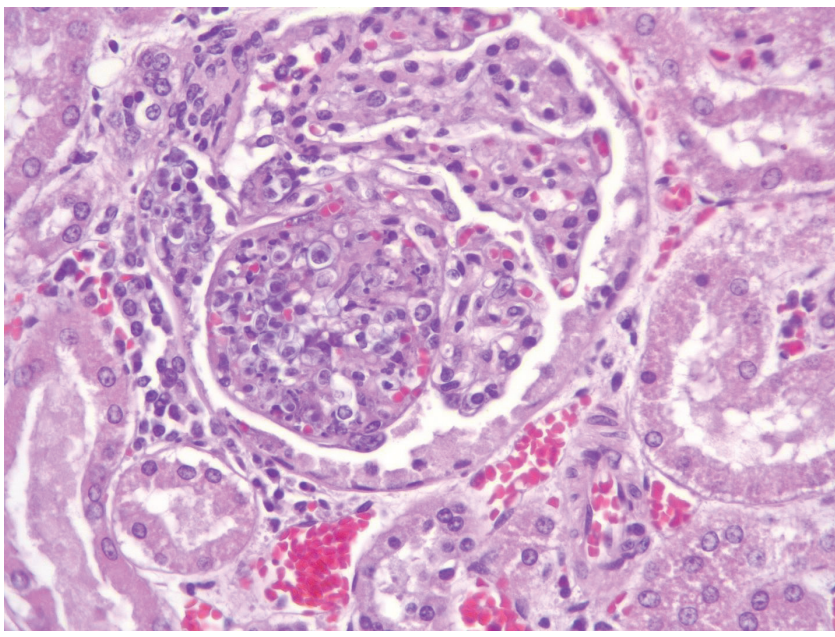

Fig. 13. Histopatología de riñón, glomerulonefritis piogranulomatosa, dilatación del espacio urinario glomerular con infiltración de múltiples esporangios, Prototheca zopfii en el mesangio glomerular H\&E (400x). (Alfaro-Alarcón, A., 2021).

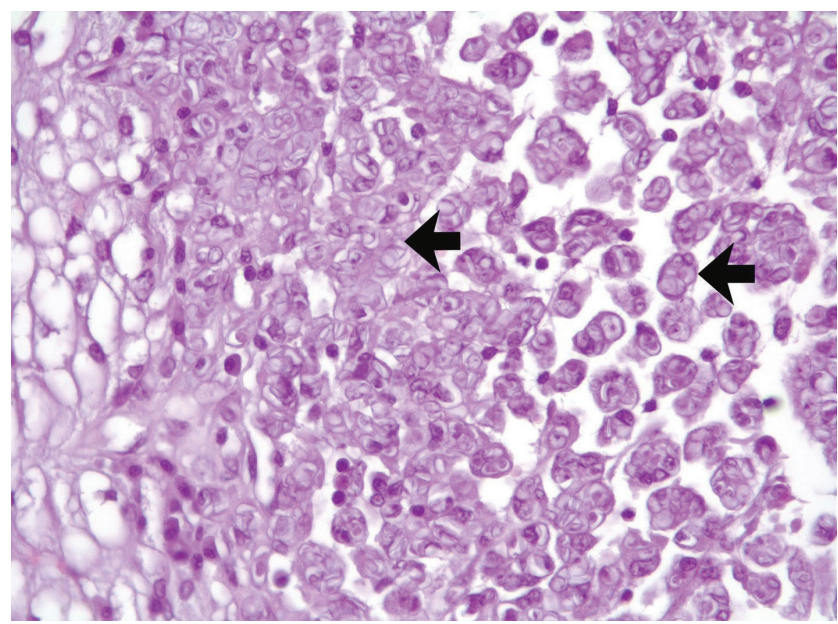

Fig. 12. Histopatología de globo ocular, retina, masiva cantidad de esporangios con múltiples endosporas, Prototheca zopfii H\&E (200x). (Alfaro-Alarcón, A., 2021).

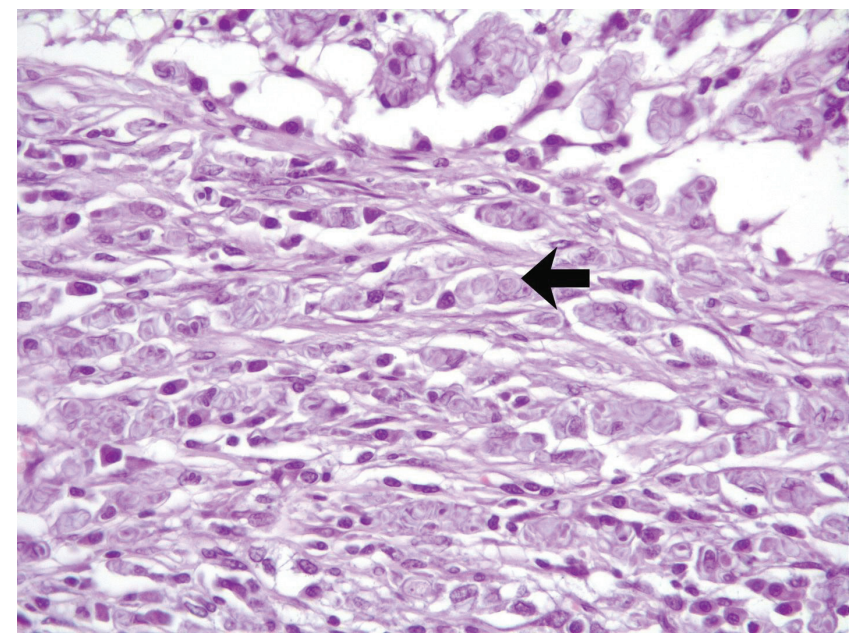

Fig. 14. Histopatología de globo ocular retina, presencia masiva de estructuras esporangios con citoplasma magenta rodeado por una cápsula clara H\&E (400x). (AlfaroAlarcón, A., 2021).

\section{Endoscopía}

Los posibles hallazgos, al realizar una colonoscopia, son: hiperemia difusa, erosiones de diferente profundidad, úlceras, hemorragia (Fig. 15); edema, engrosamiento de la mucosa (Fig. 16); con o sin presencia de tejido friable, aumento de la granularidad de la mucosa (Fig. 17); presencia de moco, nódulos blanquecinos (Fig. 18) 
y áreas isquémicas y necróticas (Bottero et al., 2016; Greene, 2012; Palm, 2014; Strunck et al., 2004). Se prefiere tomar muestras, del colon descendente, con un endoscopio rígido de $2.8 \mathrm{~mm}$, dado que permite tomar muestras grandes y profundas. Lo recomendable es que la biopsia sea del grosor total de la mucosa. Se debe preparar el colon adecuadamente para la correcta visualización de la mucosa (Nelson \& Couto, 2014).

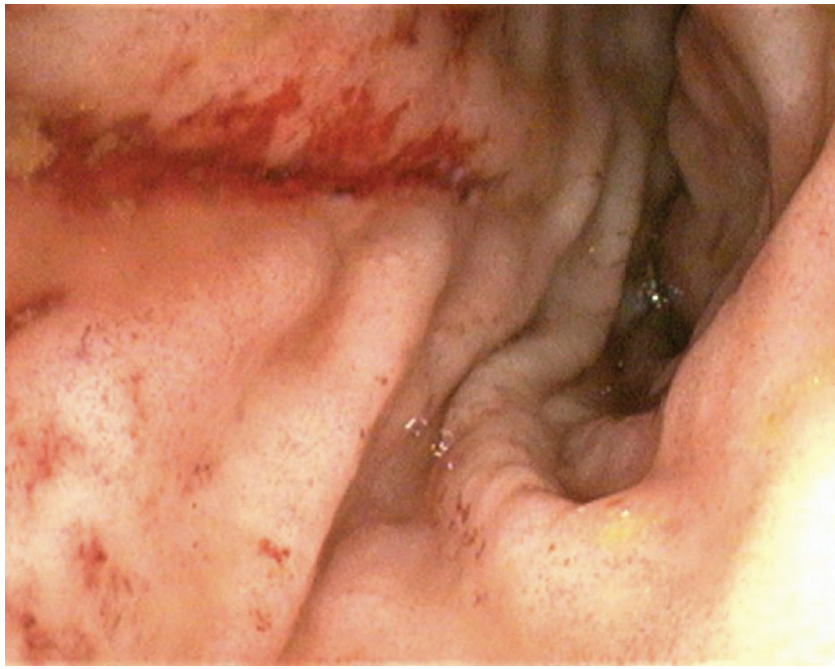

Fig. 15. Endoscopia de un canino con prototecosis, a nivel de colon transverso, donde se observa hiperemia diseminada, erosiones superficiales y ulceración longitudinal, con presencia de hemorragias. (Valverde-Altamirano, E., 2020).

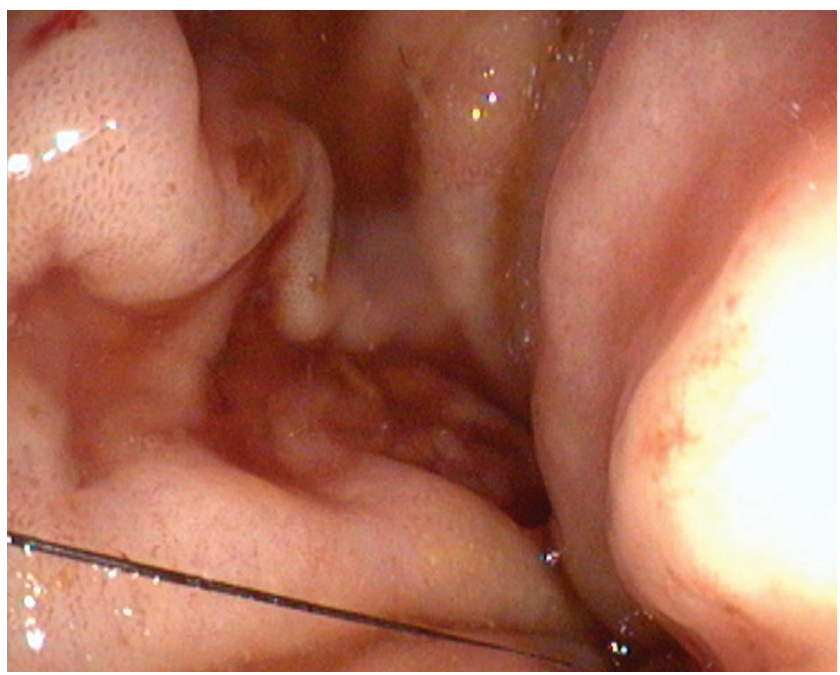

Fig. 17. Endoscopia de un canino con prototecosis, en el colon descendente con aumento de granularidad y restos hemáticos. (Valverde-Altamirano, E., 2020).

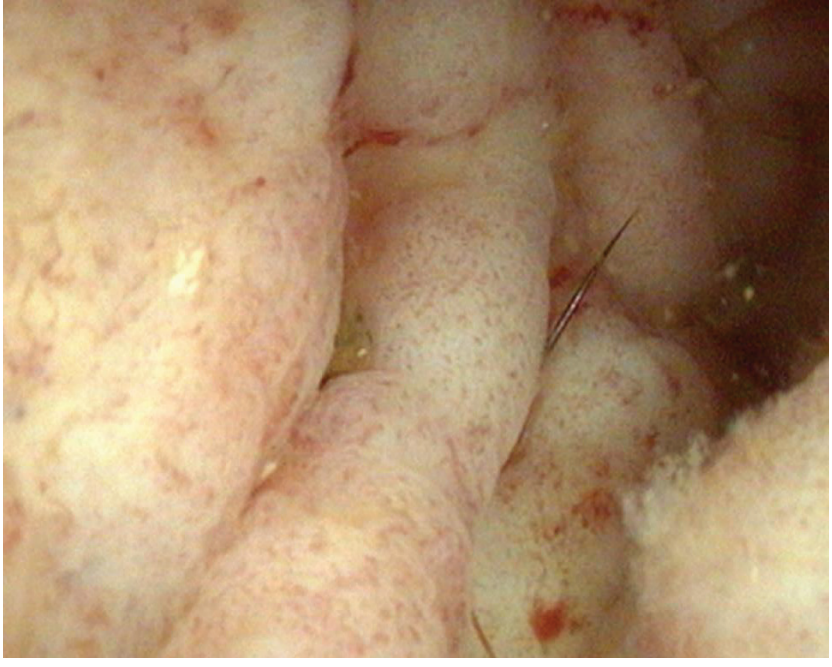

Fig. 16. Endoscopia de un canino con prototecosis, a nivel de colon ascendente, tratado con inmersión de agua temperada. Se observa edema, congestión y aumento de grosor de mucosa. (Valverde-Altamirano, E., 2020).

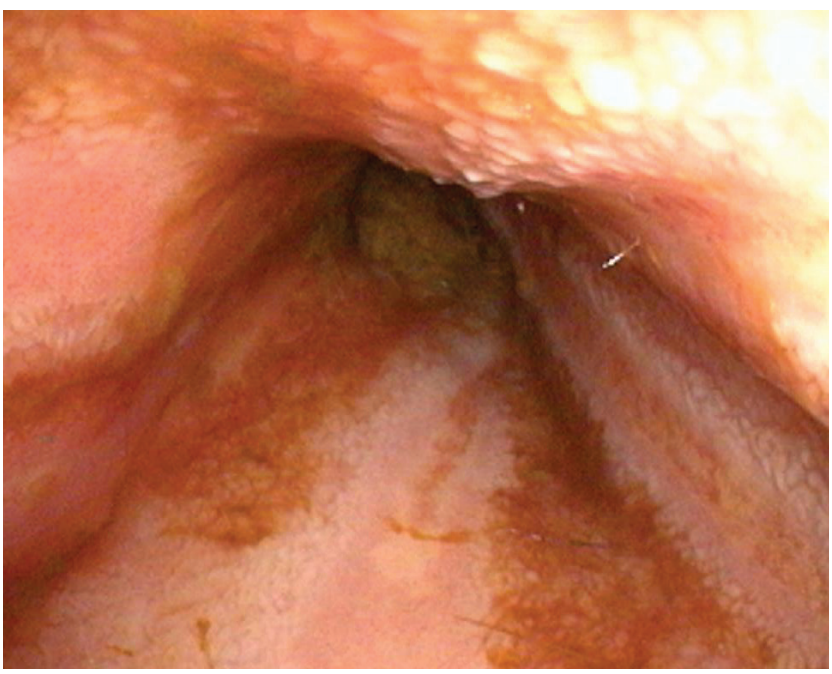

Fig. 18. Endoscopia, recto, nódulos blanquecinos, presencia de moco y restos hemáticos. De un caso de prototecosis canina (Valverde-Altamirano, E., 2020). 


\section{Diagnóstico microbiológico}

Los métodos de diagnóstico microbiológico, para la identificación de la especie, son: el cultivo, métodos bioquímicos, inmunofluorescencia directa, PCR, espectrofotometría de masas y microscopía electrónica (Carfora et al., 2017; Strunck et al., 2004; Young et al., 2012).

En citologías, la observación de estructuras ovales, esféricas o elípticas no gemantes en montajes al fresco, con azul de lactofenol (Fig. 19a), azul de metileno, hidróxido de potasio (KOH) del 10 al 40\% (Fig. 19b), tinción de Gram (Fig. 19c), Giemsa (Fig. 19d) o Wright, confirman la presencia de este agente (Samanta, 2015; Walsh et al., 2018).

Las algas del género Prototheca crecen en Agar Sabouraud Dextrosa (SDA) a $30{ }^{\circ} \mathrm{C}$, entre las 24 a 72 horas (Fig. 20) y son inhibidas por la cicloheximida. Las especies patógenas como $P$. zopfii y $P$. wickerhamii se pueden distinguir de las no patógenas porque las primeras crecen a $37^{\circ} \mathrm{C}$, mientras que las otras no pueden crecer a esa temperatura y presentan cápsula (Walsh et al., 2018).
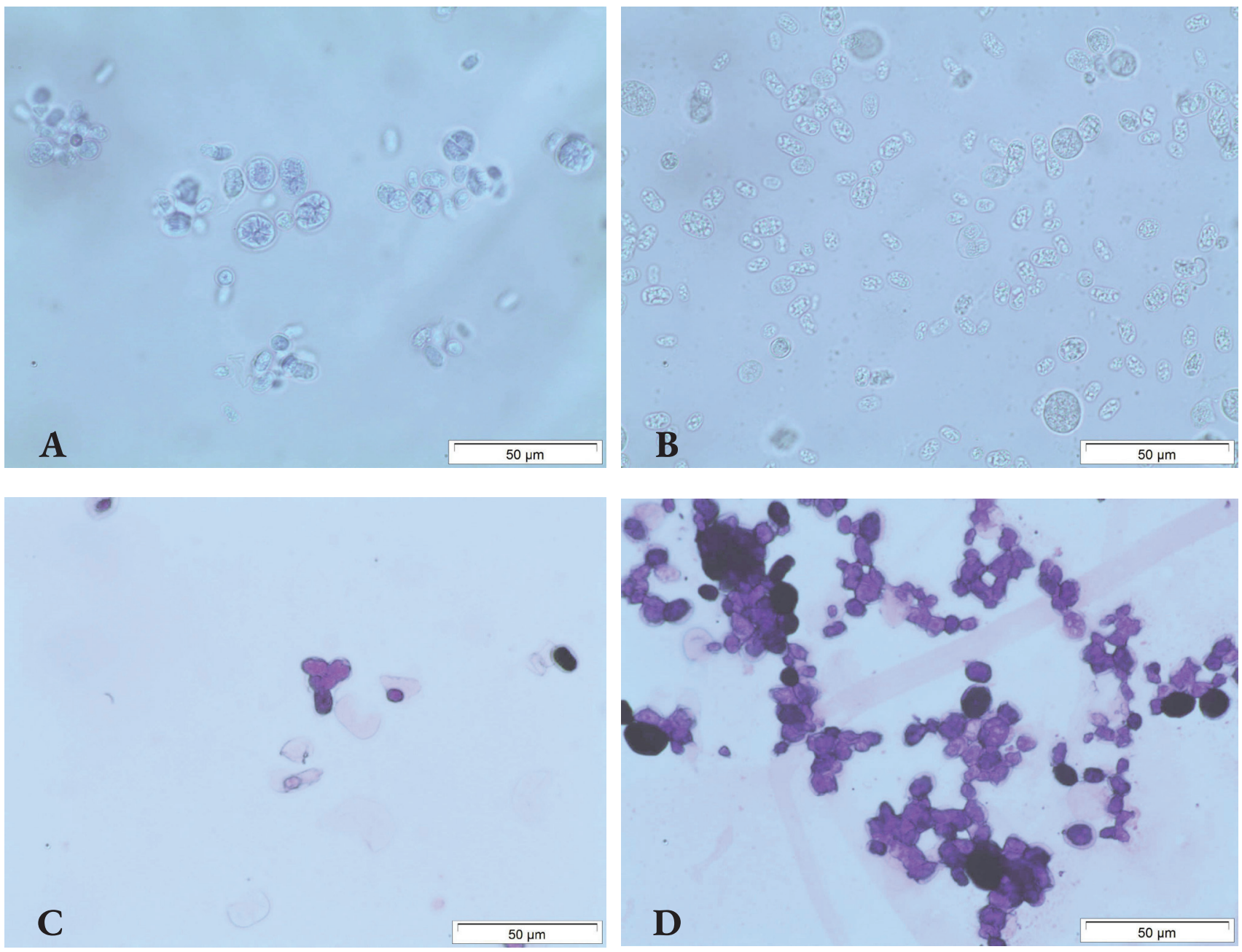

Fig. 19. Morfología microscópica de Prototheca zopfii a partir de SDA $37^{\circ} \mathrm{C}$ a las 72 horas. A. Azul de lactofenol $60 x$. B. KOH $10 \%$ 60x. C. Tinción de Gram 60x. D. Tinción de Giemsa 60x. (Calderón-Hernández, A., 2020). 


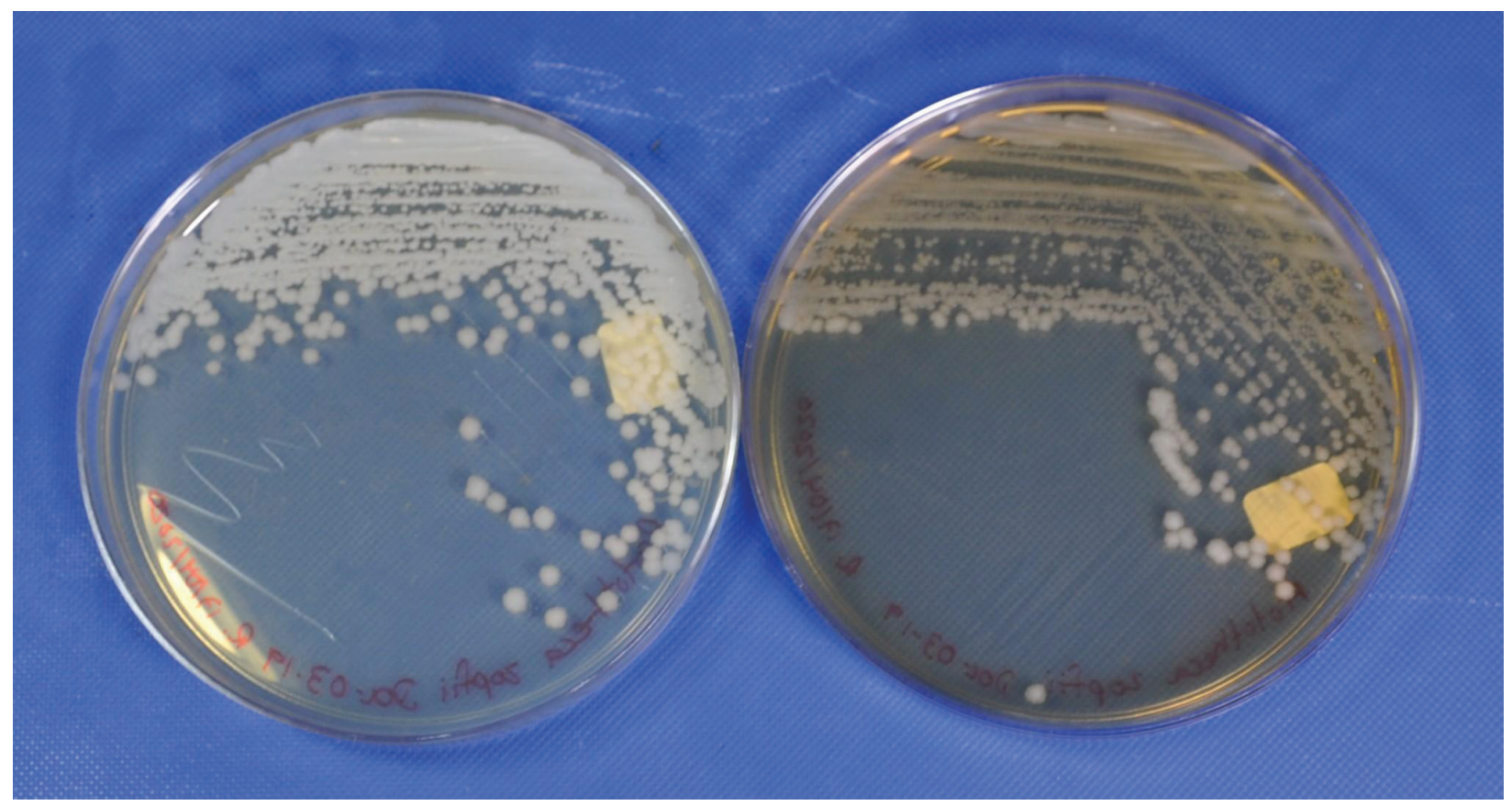

Fig. 20. Aislamiento de P. zopfii en Agar Sabouraud Dextrosa y Agar Extracto de Malta, luego de 72 horas de incubación a $28^{\circ} \mathrm{C}$. (Alfaro-Alarcón, A., 2021).

\section{Identificación bioquímica}

Tradicionalmente, estas algas se han identificado mediante métodos bioquímicos por la asimilación de azúcares como: la glucosa, galactosa y trehalosa. En el mercado costarricense existen kits comerciales que permiten la identificación de esta alga, así el Api 20C AUX identifica $P$. wickerbamii, pero no P.zopfii y el Vitek 2 Compact identifica P. wickerhamii y P.zopfii (bioMérieux, 2010; bioMérieux, 2020).

Según la tabla de identificación del sistema Api 20 C AUX, el 100\% de los aislamientos de P. wickerhamii reaccionan de forma positiva a las 28 o 72 horas en los siguientes pocillos: D-glucosa (GLU), glicerol (GLY) y D-trealosa (TRE) y un 55\% en galactosa (GAL) (bioMérieux, 2010). Con respecto al Vitek 2 Compact, las tarjetas Vitek 2 YST permiten realizar la identificación de $P$. zopfii y $P$. wickerhamii (bioMérieux, 2020) por asimilación bioquímica de alrededor de diez azúcares, en las que $P$. wickerbamii a diferencia de $P$. zopfi utiliza dTREa y dGALa, lo que coincide con lo descrito por la literatura (Walsh et al., 2018) (Cuadro 1).

\section{Métodos moleculares}

\section{MALDI-TOF MS}

Distintos autores han realizado análisis por espectrofotometría de masas por desorción/ionización láser asistida por matriz y detector de iones (MALDI-TOF MS) con buenos resultados (Ahrholdt et al., 2012, Bonifaz et al., 2019). 


\section{Reacción en Cadena de la Polimerasa (PCR)}

El diagnóstico molecular se realiza a partir de un aislamiento previamente purificado en $\mathrm{SDA}$ a $37^{\circ} \mathrm{C}$, cuyo $\mathrm{ADN}$ es extraído mediante un kit comercial DNeasy Plant Mini Kit (Qiagen, GmbH, Alemania) y la PCR basada en el gen $18 \mathrm{~S}$ del ADN ribosomal se realiza con cebadores específicos para la identificación de este género (Cuadro 2).

Cuadro 1. Reacciones positivas de asimilación bioquímica mediante Vitek 2 Compact realizadas en el Laboratorio de Micología de la Escuela de Medicina Veterinaria de la Universidad Nacional entre 2015 a 2019. (Calderón-Hernández, A., 2020).

\begin{tabular}{|c|c|c|c|c|}
\hline \multirow[t]{2}{*}{ Reactivo } & \multicolumn{4}{|c|}{ Identificación (\% Probabilidad) } \\
\hline & P. zopfii $(96)^{*}$ & P. zopfii (99) ${ }^{* *}$ & P. zopfii $(99)^{* * *}$ & P. wickerhamii $(95)^{* * * *}$ \\
\hline dGLUa & + & + & + & + \\
\hline IGLTa & + & + & + & + \\
\hline IPROa & + & + & + & + \\
\hline XLTa & + & + & - & - \\
\hline dTREa & - & - & - & + \\
\hline $2 \mathrm{KGa}$ & - & + & - & + \\
\hline LeuA & + & + & + & + \\
\hline LATa & + & + & + & - \\
\hline ARG & + & + & + & + \\
\hline $\mathrm{ACEa}$ & + & + & + & + \\
\hline dGALa & - & - & - & + \\
\hline GLYLa & + & + & + & + \\
\hline
\end{tabular}

Cuadro 2. Oligonucleótidos utilizados para la identificación molecular de Prototheca spp. (Calderón-Hernández, A., 2020).

\begin{tabular}{lllll}
\hline Cebador & Dirección 5'a 3' & Peso Molecular & Identificación & Referencia \\
\hline Proto 18-4/f & GACATGGCGAGGATTGACAGA & $150 \mathrm{pb}$ & P. zopfii genotipo 1 & $\begin{array}{l}\text { Ricchi et al. 2010; Ah- } \\
\text { rholdt et al. 2012 }\end{array}$ \\
PZ GT I/r & GCCAAGGCCCCCCGAAG & & & \\
Proto 18-4/f & GACATGGCGAGGATTGACAGA & $165 \mathrm{pb}$ & P. zopfi genotipo 2 & $\begin{array}{l}\text { Ricchi et al. 2010; Ah- } \\
\text { rholdt et al. 2012 }\end{array}$ \\
PZ GT II/r & GTCGGCGGGGCAAAAGC & & & Picchi et al. 2010; Ah- \\
IK/f & CAGGGTTCGATTCCGGAGAG & $126 \mathrm{pb}$ & $\begin{array}{l}\text { P. blascheae } \\
\text { P. stagnora }\end{array}$ & rholdt et al. 2012 \\
GT III/r & GTTGGCCCGGCATCGCT & & & \\
\hline
\end{tabular}




\section{Tratamiento}

No existe un medicamento eficaz para tratar a este agente. Históricamente, se ha utilizado antifúngicos, con poco éxito, pues estos antifúngicos actúan sobre la membrana citoplasmática fúngica, inhibiendo la síntesis del ergosterol, molécula ausente en las algas (Plumb, 2018a; Plumb, 2018b). La anfotericina B, junto con el itraconazol, se destacan entre los tratamientos que han tenido una mejor respuesta; mientras que el ketoconazol y fluconazol suelen ser menos efectivos. En general, esos antifúngicos no desarrollan cura en la mayoría de los casos. En relación con el cuadro clínico cutáneo, en casos de un único nódulo, la escisión quirúrgica amplia es curativa. En caso de ser varios nódulos cutáneos, la escisión quirúrgica no es recomendada (Font et al., 2014; Greene, 2012; Stenner et al., 2007; Strunck et al., 2004; Young et al., 2012; Vince et al., 2014). Diagnósticos, tratamientos tardíos, agentes inmunosupresores y una pobre respuesta a fármacos, son reportadas durante fallas terapéuticas (Font et al., 2014; Vince et al., 2014).

En el Laboratorio de Micología de la Escuela de Medicina Veterinaria de la Universidad Nacional, se realizó pruebas de sensibilidad antifúngica mediante Vitek 2 Compact a algunos aislamientos, en los que se obtuvo concentraciones mínimas inhibitorias (MIC) muy elevadas, dado que la mayoría se encontró en la dilución mínima o cercana a ella (Cuadro 3).

Cuadro 3. Concentraciones mínimas inhibitorias de aislamientos de Prototheca zopfii y P. wickerbamii aislados en el Laboratorio de Micología de la Escuela de Medicina Veterinaria durante 2014 a 2019. (Calderón-Hernández, A., 2020).

\begin{tabular}{lccccc}
\hline Antifúngico & \multicolumn{5}{c}{ Concentración mínima inhibitoria (\% Probabilidad) } \\
& P. zopfii $(96)^{*}$ & $P$. zopfii $(99)^{* *}$ & $P$. zopfii $(99)^{* * *}$ & P. wickerbamii $(95)^{* * * *}$ & $\begin{array}{c}\text { Dilución } \\
\text { Mínima - máxima**** }\end{array}$ \\
\hline Fluconazol & 32 & $>=64$ & $<=0.1$ & TRM & $64-0.13$ \\
Voriconazol & $<=0.12$ & $<=0.12$ & $<=0.12$ & TRM & $8-0.016$ \\
Caspofungina & $>=4$ & $>=4$ & $<=0.25$ & $>=4$ & $4-0.008$ \\
Micafungina & $>=4$ & $>=4$ & $<=0.06$ & $>=4$ & $4-0.008$ \\
Anfotericina B & 0.5 & $<=0.12$ & 1 & TRM & $4-0.008$ \\
Flucitocina & $>=64$ & $>=64$ & $<=1$ & TRM & $64-0.13$ \\
\hline
\end{tabular}

* Bionúmero: 450010002005110

** Bionúmero: 4500100000005130

*** Bionúmero: 4500100000005110

**** Bionúmero: 4502100020201130

*****Fuente: Dromer et al. 2016.

\section{Situación en Costa Rica}

En Costa Rica, esta enfermedad fue subdiagnosticada por un largo período, con escasos reportes. El primer reporte de prototecosis, en Costa Rica, fue en 1997, en un canino que presentaba infección sistémica (Berrocal et 
al., 1997). En el 2006, se reportó el caso de un caprino con prototecosis intestinal, en el Servicio de Patología de la Escuela de Medicina Veterinaria de la Universidad Nacional (SP EMV-UNA). Posteriormente, Solano-Quesada (2009) reportó, en un estudio ganado lechero en Costa Rica, de los cuales el $1.1 \%$ (4/363) de los aislamientos de mastitis clínicas fueron causadas por Prototheca spp. Luego, Calderón-Hernández (2010), aisló Prototheca spp. de un hisopado cloacal de una tortuga semiacuática de orejas rojas (Trachemys scripta Elegans) y de una biopsia de pulmón de una tortuga candado (Kinosternon scorpioides). En el Laboratorio de Micología, de la Escuela de Medicina Veterinaria de la Universidad Nacional, se tiene registro de dos caninos con signos gastrointestinales, en el 2014 y 2016, en los que se aisló Prototheca zopfii (Calderón-Hernández \& Urbina Villalobos, 2019). En el 2019 , se presentaron cuatro casos de prototecosis. Uno de los casos presentaba alteraciones en el equilibrio, uveítis con desprendimiento de retina, una lesión en el cornete nasal y hematoquecia no responsiva a antibióticos. Estos últimos casos, se diagnosticaron basándose en cultivo, histopatología y el sistema automatizado VITEK 2. Basados en estos casos, la posibilidad de prototecosis, a nivel nacional, es una posibilidad real.

\section{Conclusiones}

El diagnóstico de la prototecosis ha incrementado, en los últimos años, gracias a un mayor acceso a las herramientas diagnósticas disponibles en Costa Rica. El abordaje certero requiere del uso de técnicas como: la endoscopía, histopatología, cultivo y biología molecular. La baja excreción del agente y distribución tisular multifocal, en etapas tempranas de la enfermedad, dificulta su diagnóstico en las etapas agudas; lo cual conlleva a que la mayoría de los cuadros estén cursando la etapa crónica de la enfermedad. A la fecha, el tratamiento es poco efectivo y no curativo en la mayoría de los casos; por lo cual, el pronóstico es desfavorable. Debido a que la prototecosis no es una enfermedad de reporte obligatorio en Costa Rica,, la epidemiología de prototecosis permanece como una incógnita.

\section{Referencias}

Ahrholdt, J., Murugaiyan, J., Straubinger, R.H., Jagielski, T., \& Roesler, U. (2012). Epidemiological analysis of worldwide bovine, canine and human clinical Prototheca isolates by PCR genotyping and MALDITOF mass spectrometry proteomic phenoty ping. Medical Mycology, 50, 234-243. https://doi.org/10. $\underline{3109 / 13693786.2011 .597445}$

Berrocal, A., Rodríguez, J. \& Valverde, A. (1997). Prototecosis sistémica en un canino. Descripción patológica de un caso. Archivos de Medicina Veterinaria, 29(2), 307-312. https://doi.org/10.4067/ $\underline{\text { S0301-732X1997000200017 }}$

BioMérieux. (2010). Api 20 C AUX 07628H- xl-2010-02. Marcy-l’Etoile: BioMérieux.

BioMérieux. (2020, 28 de julio). Tarjetas de identificación VITEK 2 YST. https://www.biomerieux.es/ diagnostico-clinico/productos/tarjetas-de-identificacion-de-vitekr2-yst

Bonifaz, A., Montelongo-Martínez, F., Araiza, J., González, G.M., Treviño-Rangel, R., Flores-Garduño, A., Camacho-Cruz, A., \& Tirado-Sánchez A. (2019). Evaluación de MALDI-TOF MS para la identificación de levaduras patógenas oportunistas de muestras clínicas. Revista Chilena de Infectología, 36(6), 790-793. http://dx.doi.org/10.4067/S0716-10182019000600790 


\section{Ciencias}

Bottero, E., Mercuriali, E., Abramo, F., Dedola, B., Martella, V. \& Zini, E. (2016). Fatal protothecosis in four dogs with large bowel disease in Italy. Wiener Tierärztlichen Monatsschrift. 103, 17-21.

Calderón-Hernández, A. (2010). Identificación de agentes micóticos en animales silvestres en Costa Rica: estudio preliminar. [Tesis de licenciatura, Universidad Nacional]. Repositorio Académico Institucional de la Universidad Nacional https://www.repositorio.una.ac.cr/bitstream/handle/11056/12975/ Alejandra-Mar\%c3\%ada-Calderon-Hern\%c3\%a1ndez.pdf?sequence=1\&isAllowed=y

Calderón-Hernández, A., \& Urbina-Villalobos, A. (2019, 28-30 de abril). Frequent and infrequent mycosis in small animal practice of Costa Rica. [Presentación oral.] 35th World Veterinary Association Congress, San José, Costa Rica.

Carfora, V., Noris, G., Caprioli, A., Iurescia, M., Stravino, F. \& Franco, A. (2017). Evidence of a Prototheca zopfii genotype 2 disseminated infection in a dog with cutaneous lesions. Mycopathologia. 182(5-6), 603-608. https://doi.org/10.1007/s11046-016-0108-2

Dromer, F., Desnos-Ollivier, M., Alomoussa, M \& K'ouas, G. (2016, 21 de marzo -16 de abril). Antifungal susceptibility testing. [Bench Session]. Medical Mycology Course. París: Pasteur Institute.

Ettinger, S.J, Côté, E. \& Feldman, E.C. (2010). Textbook of veterinary internal medicine disease of the dog and cat. $\left(8^{\text {th }}\right.$. ed.). Elsevier.

Font, C., Mascort, J., Márquez, M., Esteban, C., Sánchez, D., Durall. N., Pumarola, M. \& Luján, A. (2014). Paraparesis as initial manifestation of a Prototheca zopfii infection in a dog. Journal of Small Animal Practice, 55(5), 283-286. https://doi.org/10.1111/jsap.12188

Greene, C.E. (2012). Infectious Diseases of the Dog and Cat. (4 $4^{\text {th }}$. ed.). WB Saunders.

Hollingsworth, S. (2000). Canine protothecosis. Veterinary Clinics of North America: Small Animal Practice, 30(5), 1091-1101. https://doi.org/10.1016/s0195-5616(00)05008-7

Manino, P., Oliveira, F., Ficken, M., Swinford, A. \& Burney, D. (2014). Disseminated protothecosis associated with diskospondylitis in a dog. Journal of the American Animal Hospital Association, 50(6), 429-435. https://doi.org/10.5326/JAAHA-MS-6083

Macedo, J. T., Riet-Correa, F., Dantas, A. F., \& Simoes, S. V. (2008). Cutaneous and nasal protothecosis in a goat. Veterinary Pathology, 45 (3), 352-354. https://doi.org/10.1354/vp.45-3-352

Nelson, R.W. \& Couto, C.G. (2014). Small animal internal medicine. (5 ${ }^{\text {th }}$. ed.). Elsevier.

Palm, V. (2014). Entwicklung eines indirekten ELISA-Testsystems zur Serodiagnostik der caninen Protothekeninfektion und nachfolgender Untersuchung der Prävalenz der caninen Protothekose. (Publicación No. 3746) [Tesis doctoral, Freien Universität Berlin] Refubium. https://refubium.fuberlin.de/bitstream/handle/fub188/9752/Palm_online.pdf? sequence=1\&isAllowed $=y$

Plumb, D.C. (2018a). Amphotericin B. En D.C. Plumb (Ed.), Plumb's Veterinary Drug Handbook. (9 Ed., pp. 69-73). Wiley-Blackwell.

Plumb, D.C. (2018b). Itraconazole. En D.C. Plumb (Ed.), Plumb's Veterinary Drug Handbook. (9 Ed., pp. 642-645). Wiley-Blackwell. 
Pressler, B. M., Gookin, J. L., Sykes, J. E., Wolf, A. M., \& Vaden, S. L. (2005). Urinary tract manifestations of protothecosis in dogs. Journal of Veterinary Internal Medicine, 19 (1), 115-119. https://doi. org/10.1892/0891-6640(2005)19<115:utmopi $>2.0 . c 0 ; 2$

Ribeiro, M., Rodrigues, M., Roesler, U., Roth, K., Rodigheri, S., Ostrowsky, M., Salerno, T., Keller, A. \& Fernandes, M. (2009). Phenotypic and genotypic characterization of Prototheca zopfii in a dog with enteric signs. Veterinary Research, 87(3), 479-481. https://doi.org/10.1016/j.rvsc.2009.04.015

Ricchi, M., Goretti, M., Branda, E., Cammi, G., Garbarino C.A., Turchetti, B., Moroni, P., Arrigoni, N., \& Buzzini, P. (2010). Molecular characterization of Prototheca strains isolated from Italian dairy herds. Journal of Dairy Science, 93, 4625-4631. https://doi.org/10.3168/jds.2010-3178

Samanta, I. (2015). Prototheca. En Samanta, I. Veterinary Mycology. (pp. 11-153) Springer.

Schöniger, S., Roschanski, N., Rösler. U., Vidovic, A., Nowak, M., Dietz, O., Wittenbrink, M.M., \& Schoon, H.A. (2016). Prototheca species and Pithomyces chartarum as causative agents of rhinitis and/ or sinusitis in horses. Journal of Comparative Pathology, 155(2-3), 121-125. https://doi.org/10.1016/j. jсра.2016.06.004.

Solano-Quesada, L. (2009). Identificación de las bacterias causantes de mastitis y su patrón de sensibilidad a diferentes antibióticos, en vacas de hatos lecheros de Costa Rica asociados a la Cooperativa de Productores de Leche Dos Pinos R.L. [Tesis de licenciatura, Universidad Nacional]

Souza, L., Estrela-Lima, A., Moreira, E., Ribeiro, L., Xavier, M., Silva, T., Costa, E. \& Santos, R. (2009). Systemic canine protothecosis. Brazilian Journal of Veterinary Pathology, 2(2), 102-106.

Stenner, V.J., Mackay, B., King. T., Barrs, V.R., Irwin, P., Abraham, L., Swift, N., Langer, N., Bernays, N., Hampson, E., Martin, P., Krockenberger, M.B., Bosward, K., Latter, M. \& Malik, R. (2007). Protothecosis in 17 australian dogs and a review of the canine literature. Medical Mycology, 45(3), 249-266. https://doi.org/10.1080/13693780601187158

Strunck, E., Billups, L. \& Avgeris. S. (2004). Canine protothecosis. Compendium: Continuing Education for Veterinarians, 26(2), 96-102.

Vince, A.R., Pinard, C., Ogilvie, A.T., Tan, E.O. \& Abrams-Ogg, A.C. (2014). Protothecosis in a dog. Canadian Veterinary Journal, 55(10), pp. 950-954.

Walsh, T.J., Hayden, R.T., \& Larone, D.H. (2018). Larone's medically important fungi. A guide to identification. $\left(6^{\text {th }} \cdot\right.$ ed.). ASM Press.

Young, M., Bush, W., Sanchez, M., Gavin, P. \& Williams, M. (2012). Serial MRI and CSF analysis in a dog treated with intrathecal amphotericin B for protothecosis. Journal of the American Animal Hospital Association, 48(2), 125-131. https://doi.org/10.5326/JAAHA-MS-5701 